\title{
Delivery of two normal twins exposed to imatinib and nilotinib during the first trimester of pregnancy in a woman with chronic myeloid leukemia
}

\author{
S Hadiji Mseddi ${ }^{1}$, F Kallel ${ }^{1}$, H Amouri ${ }^{2}$, H Affes ${ }^{3}$, M Mdhaffar ${ }^{1}$, M Elloumi $^{1}$ \\ 1. Hematology Department, Hedi Chaker Hospital, Faculté de Médecine de Sfax, University of Sfax, Tunisia. 2. Gyneco \\ obstetrical Department, Hedi Chaker Hospital, Faculté de Médecine de Sfax, University of Sfax, Tunisia. 3. Pharmacology \\ Department, Faculté de Médecine de Sfax, University of Sfax, Tunisia
}

Correspondence: Sondes Hadiji Mseddi. Address: Hematology Department, Hedi Chaker Hospital, Route El Ain 3029, Sfax, Tunisia. Telephone: 002-167-424-0549. Fax: 002-167-424-0549. E-mail: sondes.mseddi@rns.tn

Received: May 9, 2012

Accepted: June 24,2012

Published: September 1, 2012

DOI : $10.5430 /$ jhm.v2n3p74

URL: http://dx.doi.org/10.5430/jhm.v2n3p74

\section{Abstract}

We report here the case of a 35-year-old woman. She was diagnosed with Philadelphia chromosome-positive chronic myeloid leukemia. Because of primary infertility, she received imatinib without contraception. Complete cytogenetic response was not obtained with $800 \mathrm{mg} / \mathrm{day}$. As a result, the patient was switched to nilotinib at $400 \mathrm{mg}$ twice a day. An accidental pregnancy was identified at a term of 9 weeks while the patient was on imatinib during the first 4 weeks then nilotinib between 5th and 9th weeks of gestation. Because the patient elected to continue the pregnancy to term, nilotinib was discontinued; no further treatment was given until delivery. A follow-up with ultrasound scans was unremarkable. She successfully gave birth to female twins at 38 weeks with no malformation until 13 months post- partum. This experience provides a useful contribution for counselling patients exposed to nilotinib during pregnancy.

The introduction of the tyrosine kinase inhibitors TKI since 1998 indisputably advanced the clinical management of chronic myeloid leukemia CML. As a result, patients who are of childbearing age and are currently being treated with TKI now find themselves contemplating reproductive opportunities that would not have otherwise been possible. Because imatinib was teratogenic in rats, in addition to general safety concerns surrounding the use of any new drug in pregnancy and the limited data available in the public domain on the outcome of pregnancies of patients exposed to imatinib, it was strongly advised that effective contraception be used during therapy to prevent pregnancy ${ }^{[1-4]}$. Moreover, there is still very insufficient data on the second generation TKIs to warrant their safety in pregnant women with CML ${ }^{[5,6]}$. We report the outcome of a patient with CML who became pregnant while receiving imatinib then nilotinib.

\section{Case description}

We report here the case of 35 years old woman. In January 2001, she was diagnosed with Philadelphia chromosome-positive chronic myeloid leukemia in the chronic phase and low Sokal score. She had been given Hydroxyurea (TKI was not available in Tunisia at that time). Because of oligospaniomenorrhea and primary infertility, the diagnosis of severe ovarian insufficiency was diagnosed in 2007. In March 2008, Imatinib became available in Tunisia; the patient was always in chronic phase, so she started imatinib at $400 \mathrm{mg}$ daily without any contraception (primary 
infertility). Complete hematological response (CHR) was not obtained (high WBC at $22 \mathrm{G} / \mathrm{l}$ without splenomegaly). The increase of dose of imatinib to $800 \mathrm{mg} /$ day allowed to achieve CHR but not complete cytogenetic response (after 18 months of treatment, $25 \%$ of metaphases were Philadelphia chromosome-positive). No mutation in bcr-abl domain was detected. Since second generation TKI were available in Tunisia, imatinib was withdrawn on September 12 th 2010 and the patient was switched to nilotinib at $400 \mathrm{mg}$ twice a day. Five weeks later (on October $18^{\text {th }}$, 2010) the patient consulted for an amenorrhea of 3 months. Ultrasound showed twin pregnancy bichorial biamniotic 9 weeks of gestation (ultrasound last menstruation period was in August $25^{\text {th }}$, 2010). So, this accidental pregnancy was identified during the first trimester of gestation at a term of 9 weeks while the patient was on imatinib during the first 4 weeks of gestation then nilotinib between 5 and 9 weeks. The patient was informed of the potential fetal toxicities of therapy. After detailed and meticulous counseling, the patient elected to continue her pregnancy, so nilotinib was stopped immediately and no further treatment was given until delivery. A follow-up with ultrasound scans during the course of the pregnancy was unremarkable. During pregnancy, the patient maintained the CHR (WBC $<10 \mathrm{G} / \mathrm{L}$ without splenomegaly), karyotype and molecular controls were not done. In April 24th 2011, she delivered via cesarean section two healthy female twins' baby weighing 2, 6 and 2, $4 \mathrm{~kg}$ with an Apgar score of 9 at 5 minutes, at gestational week 38. They were breast-fed for 1 month. At 13 months post-partum, despite their low birth weights, the patients' children have been healthy and developing normally without any evidence of congenital malformations. After 1 month delivery, the peripheral blood count was always normal and $100 \%$ of metaphases were Philadelphia chromosome-positive, the patient restarted nilotinib 400 twice a day, she is currently in complete HR and partial cytogenetic response.

In general, molecular targeted therapies are not recommended during conception because of concerns raised by animal experiments that have suggested an embryotoxic effect of these agents ${ }^{[3,5,6,7]}$. However, it remains uncertain how these effects apply to humans. Currently, much literature exists regarding the evaluation of the outcome of pregnancy while on imatinib and most cases have involved successful pregnancies after the drug is withdrawn ${ }^{[1,8]}$.The first case report of successful pregnancy with imatinib exposure was published in $2004^{[9]}$. Ault and coworkers reported on the first series of patients who conceived while receiving imatinib ${ }^{[4]}$. One of the most comprehensive data sets on the effect of imatinib on pregnancy was reported by Pyle et al ${ }^{[1]}$. In this study, imatinib was evaluated in 180 women who were exposed to treatment during pregnancy; outcomes were available for 125 patients. In total, 50\% delivered a healthy baby, 28\% elected to have a termination and $14 \%$ had a miscarriage. The thorough review of the English language literature on women who became pregnant while taking imatinib conducted by Cole et al ${ }^{[8]}$ identified a total of 217 reported pregnancy events. Of these, 171 carried their pregnancy to term, 24 had spontaneous abortions and 62 had unknown outcomes. Among the 109 pregnancies with the known outcome being that the patient intended to carry their child to term, 36 (33\%) had complications, including spontaneous abortion in 24 patients, stillbirth in 1 patient, malformations in 9 patients and low birth weight in 2 patients.

Our patient was exposed to imatinib during the four first gestation weeks leading to two healthy newborns but with low birth weight which also explained by the twin pregnancy.

Nilotinib, a potent TKI, was introduced in November 2007. It is currently classified as US Food and Drug Administration Pregnancy Category $\mathrm{D}^{[5]}$. Similar to other TKIs, the manufacturer states that nilotinib is contraindicated during conception because of concerns it may cause fetal deformities. However, the medication safety information of nilotinib in pregnancy is obtained through animal studies, which may not apply to humans. In our knowledgment, there has been only one case report of the use of nilotinib during early pregnancy ${ }^{[10]}$. It is a mother with CML who became pregnant for the second time while on nilotinib for 7.4 weeks of gestation and delivered a male infant without congenital malformations. So, our patient is one of the first reports of a successful pregnancy and delivery of a healthy newborns exposed to nilotinib between 5 to 9 weeks gestation so during the key period of embryogenesis. Her pregnancy was bichorial and biamniotic so can be considered as two pregnancies. Although nilotinib treatment did not have a negative impact on these patients and her fetus, patients receiving nilotinib should be advised to practice adequate contraception. Also, there is a very limited experience with dasatinib in women with CML who become pregnant while on therapy ${ }^{[11]}$. Our patient took Hydroxyurea for 7 years 
before the pregnancy. This is long enough for some mutations in germ cells such as ova. In terms of pregnancy threats, there are also from Hydroxyurea ${ }^{[12]}$. Despite this additional risk factor, there have been favorable outcome.

\section{References}

[1] Pye SM, Cortes J, Ault P et al. The effects of imatinib on pregnancy outcome. Blood. 2008; 111: 5505-8. PMid:18322153 http://dx.doi.org/10.1182/blood-2007-10-114900

[2] Hensley ML, Ford JM. Imatinib treatment: specific issues related to safety, fertility, and pregnancy. Semin Hematol. 2003; 40: 21-5 PMid:12783371 http://dx.doi.org/10.1053/shem.2003.50038

[3] Gleevec (imatinib mesylate) [package Insert]: East Hanover, 2001.

[4] Ault P, Kantarjian H, O’Brien S et al. Pregnancy among patients with chronic myeloid leukemia treated with Imatinib. J Clin Oncol. 2006; 24: 1204-1208. PMid:16446320 http://dx.doi.org/10.1200/JCO.2005.04.6557

[5] Tasigna: (nilotinib) [package Insert]: East Hanover, NJ: NOVARTIS Pharmaceutical Corporation, 2007.

[6] Sprycel (dasatinib) [package insert]. Princeton NB-MS, 2007.

[7] Robinson AA, Watson WJ, Leslie KK. Targeted treatment using monoclonal antibodies and tyrosine-kinase inhibitors in pregnancy. Lancet Oncol. 2007; 8: 738-43. http://dx.doi.org/10.1016/S1470-2045(07)70242-5

[8] Cole S, Kantarjian H, Ault A, Cortes JE. Successful completion of pregnancy in a patient with chronic myeloid leukemia without active intervention: a case report and review of the literature. Clin Lymphoma Myeloma. 2009; 9(4): 324-7. http://dx.doi.org/10.3816/CLM.2009.n.064

[9] Heaten E, Walkinshaw S, Clark RE. Successful outcome of pregnancy in chronic myeloid leukaemia treated with imatinib. Leuk Lymphoma. 2004; 45: 1307-8. http://dx.doi.org/10.1080/10428190310001645195

[10] Conchon M, Sanabani SS, Bendit I et al. Two successful pregnancies in a woman with chronic myeloid leukemia exposed to nilotinib during the first trimester of her second pregnancy: case study. J Hematol Oncol. 2009; 2: 42. http://dx.doi.org/10.1186/1756-8722-2-42

[11] Conchon M, Sanabani SS, Serpa M et al. Successful Pregnancy and Delivery in a Patient with Chronic Myeloid Leukemia while on Dasatinib Therapy. Adv Hematol. 2010; 2010: 136252.

[12] Zuazu J, Julia A, Sierra J et al. Pregnancy outcome in hematologic malignancies. Cancer. 1991; 67: 703-709. http://dx.doi.org/10.1002/1097-0142(19910201)67:3<703::AID-CNCR2820670329>3.0.CO;2-6 